\title{
Práticas de saúde e subjetivação: a emergência do sujeito previdenciário
}

\author{
Diego Rafael Betti Russo (1)* \\ Adriana Marcondes Machado \\ Universidade de São Paulo, Instituto de Psicologia. São Paulo, SP, Brasil
}

\begin{abstract}
Resumo: Na trilha histórica da relação dos sujeitos com a saúde, interessa-nos analisar os processos de subjetivação neste percurso e as variações nas práticas de saúde modernas. Partimos da bibliografia de pensadores da subjetividade/saúde e forjamos uma pequena história das práticas de saúde no século XX: no início do século, a saúde tem o corpo como objeto; décadas depois, agrega-se o fator risco, tornando os modos de viver objeto de controle; o avanço da ciência molecular no final do mesmo século engendra uma ambivalência à saúde, quando torna o sujeito virtualmente doente pelo risco iminente da contingência genética, e a própria tecnociência promete prever, prevenir e modificar essa condição. Nosso ponto de chegada sugere a emergência de uma noção previdenciária de saúde como um imperativo: produzir saúde incessantemente no presente para diminuir o risco e garantir mais-vida futura. Forjar-se-ia uma subjetividade previdenciária que atualiza a forma moderna de sujeito?
\end{abstract}

Palavras-chave: subjetividade, saúde, risco, futuro, sujeito previdenciário.

\section{Introdução}

O Construtor não cessa de construir nem por um momento, está sempre em posição-construtora. Mesmo que não esteja construindo no sentido estrito, mantém-se envolto nesta que é sua necessidade maior: ele pensa, elucubra, calcula, manipula, racionaliza, executa, remaneja, aprimora, faz, arrepende-se, refaz, recalcula, idealiza, faz uma vez mais, planeja, refaz outra e não faz ou refaz aquela outra. O que está em jogo, sempre, é a tentativa de concluir seu projeto maior, que é sua morada, sua grande obra: a construção ${ }^{1}$, que, embora esteja incompleta, gera grande satisfação pela grandiosidade do feito, ainda que gere também frustração e medo, pois está sempre longe do ideal final.

É difícil saber ao certo o que poderia representar a completude da obra e garantir satisfação plena; podem-se elencar algumas: a necessidade de tornar a construção totalmente segura, viabilizando os meios de eliminação de qualquer criatura externa que, em maior ou menor grau, represente ameaça de invasão; a efetuação do plano de melhorar partes da construção para torná-la eficiente ao máximo (corrigir a captação de alimentos, aperfeiçoar os corredores, planejar novos pontos de descanso e fuga, retomar projetos etc.); ou, por fim, erradicar os ruídos que conhecidas e inofensivas pequenas criaturas geram nas diversas partes da imensa construção, garantindo o silêncio absoluto de todos os cantos de sua morada:

Endereço para correspondência: diegorusso@usp.br

1 "A construção" é um conto de Franz Kafka, disparador dos argumentos fulcrais deste artigo e de onde extraímos sua personagem e a nomeamos como Construtor. "a coisa mais bela da minha construção é o seu silêncio" (Kafka, 1923/1998, p. 66). Talvez seja exatamente do silêncio que ecoe a sensação de estar tudo, se não concretizado, ao menos organizado, em equilíbrio. Seria a máxima sintonia com sua construção: imperando o silêncio, aproxima-se da ideia de paz.

Deste ponto, poder-se-ia forçar a comparação, ainda que com certo cuidado, do Construtor do conto de Kafka com o sujeito da Modernidade em sua forma-Homem ${ }^{2}$ da segunda metade do século XX, que constrói sua vida seguindo um roteiro em que também visa a garantir meios para não desatinar e evitar o ruidoso peso da insatisfação: estuda-se para garantir trabalho; trabalha-se para garantir a própria subsistência e a da família; constitui-se família para garantir a continuidade consanguínea; economiza-se para assegurar aposentadoria. Todo o percurso do roteiro é subdividido em etapas que exigem sempre enorme investimento vital e, em cada uma, um recomeço, para, quiçá, garantir a tranquilidade de um futuro silencioso.

Tudo estaria resoluto para o Construtor - assim como o Homem moderno -, se sua condição existencial estivesse envolta por uma organização externa estática, não passível de atualizações, um território cristalizado imune ao intempestivo - termo entendido aqui "como a emergência de uma diferença desestabilizadora das formas vigentes, a qual nos separa do que somos e nos coloca uma exigência de criação" (Rolnik, 1995, p. 6). Não à toa, dir-se-á "das teses principais de Kafka: a literatura como relógio que adianta" (Deleuze \& Guattari, 1975/2014, p. 108). Isso quer dizer que Kafka, ali no início do século XX,

2 O termo "Homem" designa aqui uma formação subjetiva datada, e não uma generalização para pessoas. 
já espreitava as forças intempestivas por vir que provocariam rachaduras na organização da sociedade moderna da primeira metade do século XX, estruturada pelo encadeamento institucional e pela dinâmica disciplinar (família, escola, hospital, fábrica etc.).

O Construtor, calcado no perpétuo movimento de recomeço dos investimentos vitais, está amparado por uma estrutura bem definida que transmite como, onde e por que concentrar sua energia, criando um contorno maior de sentido existencial; construir-se-ia, assim, quem sabe, sua saúde. Kafka, pois, em "A construção", adianta os ponteiros do relógio regente daquela estrutura, tensionando seus pilares e limites predefinidos, cujas bordas, se ainda longe de despedaçarem totalmente, já evidenciam sinais de fissuras de toda ordem, por onde começam a escorrer parte dos valores e imperativos daquela estrutura espacialmente cimentada e repartida por durações temporais regulares.

O relógio kafkiano adianta e desperta o Construtorsempre cansado pela exigência inerente da posiçãoconstrutora - do raro momento de descanso, sono que "já deve ser muito leve, pois um zumbido quase inaudível me acorda" (Kafka, 1923/1998, p. 87). A percepção de um zumbido baixo e incessante será a marca do tensionamento que perdurará até o fim da história, gerando um estado inédito de esgotamento ante a necessidade construtora.

Esta tensão territorial faz irromper outro tipo de exigência ao Construtor. Se antes era amparado por um roteiro que norteava as principais necessidades, possibilitando calcular o próximo movimento (primeiro um corredor novo, depois aumentar a praça, realocar alimentos), posteriormente, todo o investimento passa a se concentrar na erradicação do inusitado zumbido: "na verdade existem outros trabalhos por fazer, mas este é o mais urgente de todos, é preciso haver silêncio nos meus corredores" (Kafka, 1923/1998, p. 87). Diferentemente de outras representações de risco elencadas (seguridade, eficiência, subsistência), o zumbido não representa um risco em si, mas sua probabilidade, um estado de iminência diante do incontrolável. O Construtor vai lançar mão de produções frenéticas para erradicar a virtualidade iminente, tentando encontrar sua origem e prever sua dinâmica para cercear o intempestivo figurado como probabilidade de risco. Mas o zumbido tem movimento imanente à sua vibração sonora, perpassa os muros e os corredores da Construção: propaga-se, dissemina-se, contagia, transgride estruturas, subverte qualquer tipo de controle.

É possível extrair desse conto de Kafka processualidades que apontam para variações dos movimentos produtivos do Construtor - de uma posição-construtiva cadenciada e roteirizada a um frenesi incessante de produção mediante o risco -, que possibilitam uma analítica em torno das atualizações subjetivas do sujeito moderno em relação às produções que visam a forjar uma previdência aos riscos inerentes ao viver. Possivelmente, o traço previdenciário mais atual e rompante gira em torno da produção de saúde, pensada como um campo de experiência social estratégico, pois articula desde as instituições fechadas, até os espaços abertos das mais diversas práticas que se alocam nos interstícios da vida cotidiana, seja como um predicado (sociedade medicalizada), seja como uma plataforma consumível passível de intervenção (saúde como mercadoria e oportunidade).

Uma nova lógica de saúde que tem em vista uma previdência ao risco se conjuga a outras práticas de saúde, num momento em que estimulam-se muito mais as produções em torno da saúde do que as reprimem, alçando-as a um estatuto de positividade. Aqui a novidade se refere à aposta em outro tipo de força pela qual os sujeitos são perpassados atualmente, que tensiona e já opera nas práticas de saúde, criando um novo imperativo encarnado na oportunidade de manipular ilimitadamente a natureza orgânica pelo plano da biologia molecular. Esse novo arranjo produtivo é sustentado por promessas tecnocientíficas que incitam uma produtividade frenética no espaço-tempo presente para adquirir uma mais-valia de vida futura. Esse novo processo engendra novas práticas em saúde e variações subjetivas - efeitos que objetivamos mapear neste artigo.

Para tanto, forjamos uma pequena história sobre as práticas de saúde no século XX, partindo de uma discussão sobre a vida e a saúde como objetos do biopoder e ressaltando as consequentes variações das práticas de saúde - de uma prática institucionalizada a uma prática que passa a operar para além das instituições, mirando o futuro, prevendo e prevenindo a possível doença. Discutiremos, por fim, a aparente indissociabilidade das práticas de saúde atuais das noções de sujeito empreendedor, endividado etc., até a nossa hipótese da emergência de um sujeito previdenciário. Cremos que tal percurso analítico respaldará nossa problemática final a respeito das variações subjetivas da forma-Homem moderna.

\section{Relações de forças na constituição da forma-Homem}

Deleuze (1986/1988) analisa três formações de sujeitos produzidas historicamente ${ }^{3}$ e compostas, cada qual, por relações de forças singulares que, quando se combinam com outras forças de fora, produzem as condições de emergência de um novo sujeito, uma nova formação subjetiva: "Toda forma é um composto de relações de forças. Estando dadas forças, perguntar-se-á ... com que forças de fora elas entram em relação e, em seguida, qual a forma resultante" (Deleuze, 1986/1988, p. 132). A atualização e a sucessão das formas não se dão o tempo todo nem pela combinação de quaisquer forças. Embora elas se relacionem incessantemente, poucas são

\footnotetext{
3 Deleuze tanto sistematiza a análise de Foucault (1966/2000) em torno da episteme clássica e moderna como a faz avançar, sugerindo uma importante variação da episteme moderna e da subjetividade no final do século XX. Tal avanço - caro para nós - justifica a escolha do primeiro como principal intercessor para a discussão que se segue.
} 
as "forças de fora" que atravessam determinada formação subjetiva e fazem irromper um novo sujeito; quando sim, tal subjetivação engendra uma nova operatividade do pensamento, uma nova racionalidade.

$\mathrm{Na}$ época clássica (século XVII), os sujeitos se compunham pela relação com forças eleváveis ao infinito pela qual se extraiam e se sustentava a existência de Deus, da perfeição. Era a forma-Deus, em que o pensamento "pode ser desenvolvido até o infinito ..., numa série ilimitada, num continuum prolongável. É o signo das cientificidades clássicas .... Tais ciências são gerais, o geral indicando uma ordem de infinidade" (Deleuze, 1986/1988, p. 134). Como efeito dessa força, o pensamento operava em descrever as coisas de forma mais representacional possível, de forma enciclopédica, universal e suprema.

O processo de mutação da forma-Deus para a forma-Homem, a partir do século XIX, inicia-se quando nova força, de finitude, passa a operar e compor os seres. Se na época clássica o saber se organizava como um campo ordenado, possibilitando ao pensamento operar desdobrando continuamente o infinito em séries e linearidades, com a força de finitude, os saberes passam a se organizar por séries de oposições cujos termos não se situam mais no mesmo nível. Ou seja, não mais uma única linha contínua de pensamento, mas planos limitados, sobrepostos e ramificados: "Alguma coisa vem romper as séries, fraturar os continuuns, que não podem mais se desenvolver na superfície. É como o advento de uma nova dimensão da profundeza irredutível que vem ameaçar as ordens da representação infinita" (Deleuze, 1986/1988, pp. 135-136). A forma-Homem que toma lugar quando do encontro com a força de finitude faz emergir uma racionalidade que também comporta as séries e linearidades, porém reorganizadas em camadas limitadas e funcionando em paralelo, produzindo uma dimensão de profundeza irredutível à linearidade clássica. É a força de finitude que toca e dobra a superfície desdobrável ao infinito, produzindo uma profundidade.

Assim, pelo embate com a força de finitude, já é possível visualizar o início da organização que sustenta a ciência moderna, dando condições para uma nova disposição dos saberes em ramificações, em planos paralelos de dinamismo e evoluções, em formato arborescente: a biologia, a economia e a linguística, por exemplo, são ramificações de saberes que só puderam se constituir como cientificidade na modernidade pelo descolamento diante das noções de vida, trabalho e linguagem, tríade da qual derivam quase todos os saberes e práticas. Essa variação do pensamento se torna possível quando o sujeito na formaDeus é objetivado pela força de finitude e internaliza essa força como sua própria finitude. Subjetivação que o torna ciente da finitude, moldando-o como Homem - variação subjetiva moderna. Não mais um sujeito extensivo cuja alma se desdobra à infinitude divina, mas um sujeito compartimentalizado já ciente de seu corpo finito.

\section{A vida e a saúde como objetos do biopoder}

Quando a finitude de um corpo se descola do infinito da alma, a biologia pode produzir sua própria profundidade, dobrando a superfície contínua da História natural clássica, configurando-se como cientificidade moderna, dando nova visibilidade e dizibilidade ao campo da vida, que é instaurada nos discursos, e as práticas existenciais da forma-Homem da modernidade se tornam objeto de interesse - expansão, estímulo e controle do campo vital. Foi pela trilha das tecnologias de poder que Foucault analisou as transmutações da operatividade do pensamento da época clássica à moderna - de infinitooriginário (forma-Deus) a finito-constituinte (formaHomem) -, atento às condições que possibilitaram os seres a um jogo de dupla função: tanto sujeitos como objetos de um saber atrelado às ciências desse novo campo da vida.

A explosão demográfica e a industrialização demandaram necessárias adaptações dos mecanismos de poder para lidar com os novos processos biológicos e sociais. Assim, por um processo descontínuo e em nível local, surgiram diversas instituições que exerciam um esquadrinhamento sistemático do tempo e do espaço dos sujeitos. Foi no decorrer do século XVIII que se deu o advento de uma técnica de poder essencialmente centrada no corpo do sujeito, tornando-o objeto de análise, controle e correção. São técnicas disciplinares que trabalham ao nível do detalhe via vigilância e monitoramento, ampliando a força orgânica, visando a uma maior produtividade e, ao mesmo tempo, maior submissão pelo esgotamento das energias, canalizadas incessantemente para a adequação dos gestos e comportamento às regras dos espaços disciplinares fechados e encadeados - família, escola, convento, prisão, hospital, exército, manicômio etc. -, produzindo, assim, assujeitamento (objetivação e subjetivação). A repetição exaustiva dessa dinâmica faz as regras disciplinares se forjarem como hábito, naturalizando e internalizando moldes identitários aos sujeitos a partir do registro contínuo dos efeitos das técnicas disciplinares com o corpo, de tudo o que se faz e acontece naquele espaço, produzindo dados passíveis de análises estatísticas individuais: qual comportamento comum, qual intervenção eficaz, quem desatina etc.

O poder disciplinar é uma fábrica de sujeitar corpos, justamente pela vinculação com um molde, uma identidade, forjando e naturalizando "o indivíduo como alvo, como parceiro, como par na relação com o poder" (Foucault, 2003/2006, p. 70). A individuação é a sobreposição da norma às singularidades do corpo, moldando-o via monitoramento, registros, prevenção e punição, pela estrita distinção entre normais e anormais. É a instituição disciplinar que dá relevo ao sujeito individual:

é porque o corpo foi "subjetivado", . . . porque a função sujeito fixou-se nele . . ., porque foi normalizado, é por causa disso que apareceu algo 
como o indivíduo, a propósito do qual se pode falar, se pode elaborar discursos, se pode tentar elaborar ciências. (p. 70)

A ciência moderna se constitui em torno do processo de individuação, tornando esse corpo individual seu objeto.

Entre o fim do século XVIII e o início do XIX, emerge outra tecnologia de poder para gerir a vida da população - a biopolítica das populações. Tecnologia que foca também a vida, acoplando a disciplina dos corpos à regulamentação dos fenômenos biológicos do corpo social: "vai ser preciso modificar, baixar a morbidade, vai ser preciso encompridar a vida; estimular a natalidade" (Foucault, 1997/1999, p. 293). Configura-se uma complexa tecnologia bipartida (biopoder) caracterizada pela regulamentação das condições de vida do corpoespécie pela biopolítica e pela disciplinarização de seus indivíduos por uma anátomo-política do corpo, criando uma complementariedade funcional indispensável ao desenvolvimento do capitalismo, pela inserção dos corpos individuais aos meios de produção e pelo ajustamento dos fenômenos da população aos processos econômicos. A vida se torna alvo de intervenção e, consequentemente, a saúde do indivíduo e da população, objeto de interesse e preocupação. No limite, uma sociedade que se organiza em torno de um biopoder que disciplina e regula os fenômenos contingentes dessa nova extensividade vital.

\section{A saúde para além das instituições}

A medicina irrompe, então, como uma potente estratégia de poder, pois opera, simultaneamente, sobre a disciplina dos indivíduos e a regulamentação da espécie, seja por procedimentos na saúde dos corpos individuais, seja normatizando os modos coletivos de gerir a saúde. Isso é possível quando os saberes da medicina adquirem legitimidade científica sobre a relação dos sujeitos com a saúde, forjando uma norma.

Essa medicina se legitima como hegemônica no ocidente entre o século XIX e início do XX, compõe-se ao poder disciplinar e torna o indivíduo doente seu objeto, sustentando-se na curvatura normativa saudável/ patológico que estabelece quais são as práticas sociais normais, diferenciando-as das anômalas. Materializa-se, então, como uma clínica que compreende a doença como um "processo instalado de maneira patológica no corpo biológico de órgãos, disfuncionalizando-o como normal" (Merhy, 2009, p. 282). Esse modelo de "clínica do corpo orgânico" implica, principalmente, a disciplinarização constante dos corpos individuais ou coletivos.

$\mathrm{Se}$, por um lado, o corpo sem patologia exprime o polo normal na clínica disciplinar do indivíduo, a partir da segunda metade do século XX somente esse polo normativo não sustenta mais o ideal de saúde, que se atualiza pelas reivindicações de um direito ao próprio corpo, à própria produção de saúde, à satisfação das necessidades etc.
Configura-se um processo de insurgência contra essa intensa regulamentação e disciplinarização institucional: "o que é reivindicado e serve de objetivo é a vida, ... a vida como objeto político foi de algum modo tomada ao pé da letra e voltada contra o sistema que tentava controlá-la" (Foucault, 1976/1985, p. 136). É quando, na Europa do pósguerra, a noção de saúde se transforma "em um objeto de preocupação para os Estados .... O direito do homem de manter seu corpo em boa saúde torna-se, assim, o objeto da própria ação estatal" (Foucault, 2011, p. 375). Ocorre uma organização de políticas públicas de saúde que vem atender à demanda de saúde como direito, partilhada com o Estado. Por consequência, a reivindicação legal reorganizou o capital no entorno da saúde: "o corpo humano entrou duas vezes no mercado: primeiro pelo salário, quando vendeu sua força de trabalho; depois mediante a saúde .... dado que ele é suscetível de saúde ou doença, de bem-estar ou mal-estar, alegria ou dor" (Foucault, 2011, p. 389).

A medicina desenvolve uma funcionalidade estratégica - extensiva e intensiva - na sociedade, legitimando saberes e práticas disciplinares e regulamentares de saúde, amparada cada vez mais por políticas públicas do Estado e pelo mercado; o efeito prático não seria outro senão uma sociedade que torna positivo - pois estimula e incita - o paradigma da normalidade aos moldes do discurso médico. Com efeito, se, por um lado, os sujeitos internalizam a norma dispensando cada vez mais os limites espaciais das instituições, por outro, em meio aberto, os desvios em relação à norma têm visibilidade marginal e anômala. Os sujeitos passam a atuar preventivamente sob o risco de praticar comportamentos inadequados e desvios em relação a ser saudável. Emerge outra racionalidade clínica que incita o sujeito a se manter saudável preventivamente para não adoecer, agregando estratégias de controle sobre os modos de cuidar de si. Essa clínica, ao prescindir de um corpo adoecido e focar nos modos de vida, aloca-se no limite da fronteira de uma sociedade disciplinar quando passa a operar a com a noção do risco:

Podemos ver os indícios da dissolução da sociedade moderna acontecendo nas transformações recentes do conceito de risco . . . . Estamos aos poucos abandonando a antiga vigilância face a face de indivíduos e grupos já conhecidos como perigosos ou doentes, com finalidades disciplinares ou terapêuticas, e passando a projetar fatores de risco que desconstroem e reconstroem o sujeito individual ou grupal . . ., através da identificação de lugares estatisticamente localizáveis em relação a normas e médias. (Rabinow, 1999, pp. 144-145)

Seja em espaço fechado ou aberto (saúde como direito, regulamentação e medicalização da sociedade), é todo um processo de naturalização de determinada racionalidade em torno da produção de saúde, tornando-a um bem de consumo e de direito e, principalmente, uma instância de controle justificado e legitimado pelo fator risco. 


\section{A nova força que ronda e subjetiva}

A constituição do sujeito individualizado, a formação de um novo campo vital que irrompe tornando a vida indiscernível da produção, do direito e consumo à saúde -, a expansão intensiva da medicina e o controle dos modos de viver pelo risco já compõem parte de um novo arranjo das práticas sociais que tanto tensiona como gera abalos na sociedade moderna organizada em torno das instituições disciplinares. Nessa toada, Deleuze (1986/1988) avança sua análise das formações subjetivas, atento a uma nova força de fora que passa a circundar e que acomete a forma-Homem a partir da segunda metade do século $\mathrm{XX}$ - a forma-Homem não haveria de cessar a indelével mutação das formas, efeito da constante atualização das forças -, momento histórico em que o filósofo constata que boa parte da estrutura da modernidade já se desestabilizava quando do encontro com a nova força:

o trabalho e a vida só puderam se reunir - cada um deles - numa espécie de descolamento face à economia ou à biologia . . . . Foi preciso que $\mathrm{a}$ biologia saltasse para biologia molecular ou que a vida dispersa se reunisse no código genético ... . que o trabalho dispersado se reunisse nas máquinas cibernéticas, informáticas. (Deleuze, 1986/1988, pp. 140-141)

Se antes disso a força de finitude rompia com a linearidade da superfície infinita, formando a tripla raiz da finitude (vida, trabalho e linguagem) - possibilitando o nascimento da biologia, economia e linguística -, haverá então uma atualização subjetiva quando o sujeito moderno for atravessado pela força finito-ilimitada, que já permeia o processo de evolução cientificista, expandindo o campo da vida a uma nova extensividade quando desloca a biologia molar e orgânica para a biologia molecular, redimensionando a vida para um campo passível de ilimitadas microintervenções genéticas; "um finitoilimitado, se dermos esse nome a toda situação de força em que um número finito de componentes produz uma diversidade praticamente ilimitada de combinações" (Deleuze, 1986/1988, p. 141). Daí advêm novas técnicas de gestão e intervenção em saúde - antes restritas ao indivíduo e à espécie, sob uma estrutura molar -, forjando um plano de produção de ordem molecular.

Rabinow (1999) problematiza os reflexos desse novo plano de produção a partir de estudos sobre o projeto Genoma no fim do século XX, que buscava ofertar a oportunidade de intervenções ilimitadas para modificar destino genético. A biologia molecular proporciona um esquema exato dessa nova operação de pensamento, quando sugere a possibilidade de se produzir uma quantidade ilimitada de seres a partir de uma quantidade limitada de bases genéticas. Essa é uma ilustração rompante do atravessamento da força finito-ilimitada que ronda e também se materializa nas coisas objetivas e subjetivas. Todo um novo arranjo de valores entra em circulação, culminando em uma sociedade às voltas de um plano molecular que engendra uma biossociabilidade caracterizada pela manipulação da vida pela via das promessas biotecnológicas: se cuidar da saúde poderá viver mais, se parar de fumar, se fizer esporte etc. Essa organização social constitui grupos de interesses específicos, reunidos não mais pelas identidades institucionais, mas, fundamentalmente, segundo critérios de saúde, como performances corporais, doenças cromossômicas, longevidade etc.

A biossociabilidade oferta saberes e práticas biotecnológicas, para garantir determinada forma de gestão da saúde mediante o intempestivo, naturalizando-se como uma produção positiva que legitima como imperativo a busca por uma mais-valia do espaço-tempo vital, ou seja, por investir no presente, lançando mão das ofertas biológicas para ampliar e maximizar o tempo de vida. Qualquer investimento que atente contra a extensão, expansão e maximização da vida é questionado como uma prática negativa, ilegal ou patológica. A produção biossocial estimula e propaga a ideia da oportunidade de intervenções ilimitadas no âmbito do corpo individual, populacional e molecular, para, quiçá, transgredir alguns limites da finitude orgânica.

\section{Manipulação biotecnológica e amplificação do risco}

Essa nova lógica de produção de saúde possibilita manipular o corpo orgânico finito a partir da vasta oferta biotecnológica, contanto que em sintonia com o polo positivo de produção. Essa possibilidade de manipulação ilimitada das moléculas e genes faz emergir uma problemática crucial e irreversível na modernidade: "ou caminhamos para uma espécie de veneração ante a imensidão 'daquilo que é' ou aceitamos a possibilidade de manipulação" (Rabinow, 1999, p. 154). A questão lança o sujeito ao dilema entre aceitar sua condição biológica como natural - delineando um destino imutável -, ou então verter o caráter do natural da condição biológica. Por conseguinte, torna-se natural e legítima menos a ideia de um destino vital regido pela herança biológica, do que a oportunidade de manipular o corpo e as práticas de vida pela promessa em modular o futuro. Ou seja, o natural se torna passível de intervenções artificiais e, quando o ato de manipular se torna positivo, o que é manipulado artificialmente se torna natural. Eis a dinâmica da nova força: manipular ilimitadamente os limites da finitude do corpo orgânico natural para controle do próprio destino; manipular o destino natural de forma artificial para lograr uma vida finita, mas ilimitada. O próprio termo "manipulação" comporta uma ambivalência que já é efeito da nova força, quando manipular "infere tanto um desejo de dominar e disciplinar quanto um imperativo de aperfeiçoar o orgânico" (Rabinow, 1999, p. 154), 
pois comporta desde a racionalidade moderna de objetivação via disciplinarização, até técnicas de subjetivação normativa que possibilita uma gestão produtiva do corpo e da saúde cada vez menos em torno de espaços disciplinares, e mais de uma sociedade de controle, que "é de curto prazo e de rotação rápida, mas também contínuo e ilimitado, ao passo que a disciplina era de longa duração, infinita e descontínua" (Deleuze, 1990/1992, p. 224). Se essa outra configuração social já está às voltas com uma gestão da saúde que naturaliza a possibilidade de manipulação artificial do corpo como uma prática positiva, então a noção de um destino orgânico imutável deixa de ser natural ou se torna um problema sem importância. Pode-se pensar, então, em uma biossociabilidade de controle que não só medicaliza o corpo não adoecido (pois passível de), como faz que as noções de prevenção e risco passem a inferir a clínica de forma exponencial, mais do que a terapêutica curativa, visto o "hiato institucional entre diagnóstico e terapêutica . ... A prevenção moderna é antes de tudo um mapeamento de riscos" (Rabinow, 1999, p. 145). Se antes o risco era medido estatisticamente por variáveis objetivas a que um corpo estaria submetido (exposição/contração do corpo a alguma doença), agora o "risco não é o resultado de perigos específicos colocados pela presença imediata de uma pessoa ou um grupo de pessoas, mas sim a fusão de 'fatores' impessoais que tornam um risco provável" (p. 145). O fator risco é elevado à sua própria potência quando uma nova fórmula de cálculo agrega a probabilidade do risco da exposição de um corpo ao risco de o sujeito não produzir positivamente sua saúde. Calcula-se a probabilidade do risco para manipular, de forma previdenciária, a diminuição do risco ${ }^{4}$.

Essa nova combinatória do risco - risco objetivo multiplicado pelo risco subjetivo - dispensa os cortes normativos estáticos (normal e anormal), visto que a referência normativa se atualiza de forma fugaz quando atrelada ao ritmo evolutivo dos saberes científicos. Um sujeito que faz uso de cigarro, por exemplo, pode adquirir legitimação normalista (que investe positivamente em saúde) se alocado em uma cena na qual o foco seja especificamente discutir os malefícios do glúten (num arranjo risco-glúten, e não num arranjo riscocigarro). Contudo esse mesmo sujeito fumante que discute o risco-glúten pode perder o estatuto normal/positivo caso a ciência revele que a composição nicotina e glúten seja prejudicial à saúde, muito embora, de partida, esse sujeito fumante que discute o risco-glúten dificilmente seria considerado isento de responsabilidade por atentar à saúde por fumar e deslegitimado de investir positivamente

4 Difícil não recorrer ao exemplo da atriz Angelina Jolie, que se submeteu a uma mastectomia dupla para reduzir o risco de desenvolver câncer: "os médicos estimaram que ela tinha um risco de $87 \%$ de desenvolver câncer de mama. 'Decidi ser proativa e reduzir o risco o máximo que eu podia'... suas chances de desenvolver câncer de mama agora caíram para menos de 5\%". Recuperado de https://bbc.in/3bSvqSD em outro campo pelo desatino ao primeiro. Em uma prática de saúde que intenta prever e prevenir qualquer risco - uma saúde-previdenciária -, o corte regulador do normal e do anormal pode se tornar tão plástico e modulável quanto a forma na qual a combinatória do risco se estrutura em cada cenário. No limite, não é diferente de quando as seguradoras de automóveis revertem descontos caso os carros estejam estacionados em lugares com menos probabilidade de risco, ou seguros de saúde que estabelecem descontos para os sujeitos com menos risco de contraírem alguma doença.

\section{Uma clínica a-orgânica que mira o futuro}

Essa máquina de produção de saúde é atravessada por um processo de normalização metaestável e comporta agora a iminência do risco exponencial; uma clínica que já não foca o corpo individual orgânico e patologizado, mas os comportamentos e as combinações moleculares que tornam um corpo mais ou menos propenso às virtualidades patológicas. Rose (2007/2013) analisa duas noções básicas dessa clínica atravessada pela racionalidade da biologia molecularizada, que, articuladas, instaura uma "biolítica molecular ... formas pelas quais elementos moleculares da vida podem ser mobilizados, controlados, aos quais se podem atribuir propriedades e podem ser combinados em processos que não existiam previamente" (p. 31).

A primeira noção diz da condição de suscetibilidade do sujeito, tornando-o iminente ao risco, fabricando uma prática clínica que se caracteriza pelas tentativas de diagnosticar e tratar sujeitos no presente em relação a doenças que, conforme previsto, terão no futuro. O objeto dessa clínica é o resultado do cálculo das possíveis patologias de que um sujeito poderá ser acometido. O sujeito ainda se mantém como termo fundamental da racionalidade dessa prática clínica, seja como objeto - quando do corpo adoecido -, seja como alvo das intervenções sob a molecularidade do corpo ou normativas sob comportamentos que representem risco. A segunda noção é a condição de aprimoramento, que sugere que todos os predicados referentes ao corpo ou às estéticas existenciais são ou serão passíveis de manipulação na toada da evolução tecnocientífica. As manipulações atreladas ao risco abarcam também um mercado de consumo que abre a oportunidade de constante adequação aos imperativos, assim como modelos de felicidade e bem-estar, sujeitos mais capazes, longevos, estimulados etc., buscando sempre maneiras de maximizar os predicados positivos.

Desta feita, não seria um contrassenso pensar na emergência de uma clínica a-orgânica, visto que ela pode prescindir de um organismo para operar. É uma prática clínica que, substancialmente, calcula, mapeia e probabiliza o risco a partir do grau de suscetibilidade e de aprimoramento/manipulação. Uma racionalidade de produção de saúde que já compõe o cotidiano: quando um indivíduo possui algum familiar com hipertensão, 
por exemplo, é certo que será instruído por algum profissional, parente ou amigo sobre o risco da suscetibilidade hereditária e da urgência em agir preventivamente para evitar o risco iminente (hereditário); um indivíduo sem tal hereditariedade também será incitado a se aprimorar para minimizar a probabilidade de qualquer risco, concreto ou não. Por sua vez, um sujeito a par das mais recentes (e não conclusivas) descobertas científicas que defendem o controle do glúten opera pela mesma lógica de prevenção probabilística caso decida diminuir o glúten, tal como o exemplo da mastectomia preventiva da atriz Angelina Jolie em nota.

Ademais, a biologia molecular inferida pela probabilidade do risco faz emergir o problema temporal na produção de saúde. Na medida em que essa nova racionalidade de produção incita um sem-fim de esforços no presente com vistas a manipular o destino biológico do corpo virtualmente patologizado, acentua-se o paradoxo temporal: o sujeito pode agora "calcular os próprios processos vitais, a fim de maximizar seu funcionamento e incrementar seus resultados. Sua característica-chave é a sua visão prospectiva: essas tecnologias da vida buscam remodelar o futuro vital pela ação no presente vital" (Rose, 2007/2013, p. 34). Projeta-se, então, uma maisvalia de vida alocada no futuro por via de movimentos frenéticos e incessantes que demandam enorme energia e tempo no presente. E, se é certo que o objeto dessa clínica a-orgânica é a curvatura prospectiva do risco, então sua base é menos o organismo do que os cálculos de suas probabilidades futuras.

\section{A forma-Homem ainda resiste...}

Na operatividade dessa clínica a-orgânica, o sujeito moderno em sua forma-Homem é incitado a transgredir seu destino orgânico pela oportunidade de lograr uma vida ilimitada, ao menos no entorno de sua finitude existencial, responsável que é por gerir a produção de sua própria vida - neste caso, uma combinação de retrospectiva, prospecção e prevenção dos hábitos, manipulações no corpo ou nos costumes e cálculos probabilísticos de risco. Pois, se numa sociedade disciplinar uma instituição representa o lugar de assujeitamento por uma sistematização da produção fixa, estável e descontínua com rígidos ciclos de tempo (lógica-fábrica de subjetivação), numa biossociabilidade de controle, é a lógica-empresa que vigora e confere um regime que estimula a participação ativa por via de recompensas de desempenho, promovendo flexibilização em torno do sistema de produção e autonomia para gerir o empreendimento da vida - o que não significa mais liberdade, e sim autogoverno com margem bem estreita. A aposta é a produção se manter incessante e frenética, impulsionada pela iminência do risco que se presentifica por todos os espaços, abertos ou fechados, em tempocontínuo: "O homem não é mais o homem confinado, mas o homem endividado" (Deleuze, 1990/1992, p. 224).
Essa lógica-empresa corrobora a formação de um sujeito-empreendedor incumbido de garantir seu futuro, que logo adquire uma dívida consigo mesmo, com sua saúde, quando ofertada a possibilidade de crédito convertido na oportunidade ilimitada de expandir e maximizar os predicados e o tempo vital dentro da sabida e inevitável finitude orgânica. Sob a promessa de transgredir as manifestações intempestivas, esse sujeito é responsável por fazer a retrospectiva de suas produções passadas e prospecção das presentes para calcular quão em falta está seu desempenho ou performance. Essa dívida pode ser amortizada (quitada, nunca), contanto que a produção continue incessante; se a prospecção aponta distância do risco, o efeito é uma quitação fugaz da dívida, recobrada na cadência metaestável dos saberes que podem reaproximá-lo instantaneamente da probabilidade do risco, distanciando-o, por isso, da efetuação de uma previdência do futuro. Como numa extensão do sujeitoempreendedor, forja-se um sujeito-previdenciário.

Uma clínica que atrela o modelo de sujeitoempreendedor à iminência da probabilidade-exponencialdo-risco-de legitima e naturaliza o próprio movimento de empreender um sem-fim de previdências como prática positiva. A clínica atualizada que se faz previdenciária opera no mapeamento e na intervenção muito antes da insurgência de qualquer zumbido que subverta o silêncio dos órgãos, isto é, prescinde de qualquer sinal que indique outro funcionamento do organismo ou alguma condição emergencial de doença. Essa noção previdenciária atrelada às práticas de saúde prognostica a produtividade necessária no presente para evitar futuras doenças e morte antecipada. Ademais, se a ideia de morte ainda mantém um estatuto natural (visto que a força que ronda é a finito-ilimitada), sua precocidade não; agora, morte só é natural se incontingente ou com conhecimento de causa. A noção de cura também se transforma: se na clínica moderna de órgãos cura é o momento em que um organismo não está mais adoecido, nessa clínica a-orgânica e previdenciária a noção de cura é dispersa ao infinito, pois, no limite, não possui um correlato de condição normal, salvo no ideário: os sujeitos já estão doentes ou submetidos ao risco iminente de se tornarem doentes assintomáticos ou pré-sintomáticos.

A promessa de um empreendedorismo positivo na construção de uma vida finito-ilimitada é estrangulada simplesmente porque não há termo final que corresponda a uma saúde que vislumbre uma previdência diante do intempestivo, a não ser como eterna promessa instalada não mais na transcendência infinita (forma-Deus, alma infinita), mas numa metafísica tecnocientífica. Pois, se essa forma-Homem atualizada - empreendedora e previdenciária - fez do intempestivo imanente à existência a encarnação máxima do risco, então vida não é nada mais do que uma estrutura que oferta uma saúde ilimitada mediante a iminência do risco e o viver, o ato de empreender uma previdência em saúde a ser resgatada no futuro. Qualquer que seja o 
investimento, o sujeito-previdenciário se mantém numa espiral de movimentos dicotômicos estéreis entre risco/ aprimoramento e/ou previdência/suscetibilidade.

Por ora, contudo, o ato empreendedor construtivo ainda não pode lograr a promessa de uma vida sem risco. A atualização subjetiva calcada na construção de um sujeito-previdenciário esbarra na positividade de um imperativo que endivida e esteriliza a vida presente, realocando-a na virtualidade ilimitada do futuro. Mas, se o empreendimento de uma saúde-previdenciária só cessa quando o corpo se consome em sua finitude, o sujeito-previdenciário é aquele que, mesmo reposicionado e adaptado às variações do tempo, consegue manter certa distância da morte, ainda que respirando com muito mais dificuldade, enquanto faz por ser eterno enquanto dure.

\section{...Mas algo é desbloqueado}

Mesmo permeado pela noção de risco que já dissolvia a ideia de que a construção estaria algum dia finalizada, sua incompletude era ainda inadmissível ao Construtor. Mas agora ele será lançado a um sem-fim de dúvidas, a uma condição inédita de impotência diante do intempestivo, a um esgotamento. É quando o zumbido passa definitivamente a compor a engrenagem da posiçãoconstrutora sem proporcionar um justo acoplamento, causando fissuras, modificando os movimentos imperativos, um curto-circuito. Como uma força de fora, de nenhuma maneira está sob a égide de alguma estrutura física ou espaço fechado, não se relaciona com tecnologias de poder, com alguma possibilidade de disciplina, controle ou governo.

O Construtor então exacerba suas ações, exagera, amplifica, torna ainda mais exponencial seu esforço para controlar essa propagação ondular e sonora figurada como iminência do risco. Cansado, mas ainda esperançoso, passa a questionar a posição-construtora e tenta, ao menos, buscar "a causa real do ruído. Vou então eliminá-lo, se isso estiver ao alcance da minha força, mas se não, terei pelo menos certeza" (Kafka, 1923/1998, p. 94). A dificuldade em eliminar o zumbido desloca o investimento para a tentativa de garantir alguma certeza, um saber - qualquer tipo de previdência -, talvez pela ideia de que isso gere algum conforto futuro mediante a impossibilidade de controle presente. Acontece que o zumbido não oferece rastros para um cálculo probabilístico à sua curvatura ou qualquer resquício passível de captura que revele por onde se propaga, como se movimenta, quem/o que o produz, por que ou qual sua origem - o zumbido rompe com todas as questões básicas da racionalidade científica moderna (onde, como, quem/o que, qual, por que), desconcerta o caráter onipotente estruturante das promessas da ciência.

"Importante ou não, porém, por mais que procure não encontro nada, ou melhor: encontro demais" (Kafka, 1923/1998, p. 89). O construtor hiperdimensiona o cansaço e recalcula o grau de necessidade dos movimentos previdenciários; passa a se preocupar mais com a proporção de seu cansaço e paranoia (anunciado por seu "conflito interior"), além da consequente proximidade de um esgotamento quando percebe que nenhum prognóstico tem o efeito previdenciário: "ponho tudo de lado, já estaria satisfeito se apaziguasse o conflito interior" (Kafka, 1923/1998, p. 98). O zumbido não oferece alternativa, mas fez atualizar, em vão, a posição-construtora para uma posição-previdenciária (subjetivação). O Construtor parece tão impotente quando se propõe controlar o zumbido quanto a forma-Homem diante do intempestivo: "Cheguei ao ponto que não quero absolutamente ter certeza" (Kafka, 1923/1998, p. 106). Agora sim, esgotado, é lançado a desbloquear impasses, inventar saídas.

$\mathrm{O}$ esgotamento resgata o encontro com uma vida que é convocada sem transcendência ou refúgio em exterioridade metafísica e que oferece somente a possibilidade de seguir apostando, fazer o próximo movimento; uma vida que afirma o trágico como potência. Esgota-se aquele arranjo de vida no qual a iminência-aorisco se faz análoga à iminência-intempestiva, em que a necessidade de empreender uma previdência ao contingente se faz imperativa: "a inevitável fatalidade da vida humana nos vincula a um jogo duplo com o acaso e a necessidade. Tentar escapar deste jogo seria enredar-se na armadilha metafísica, cujo efeito é a despotencialização da vida" (Ribeiro, 2009, p. 103). Libera-se, pois, uma vida que é imanente ao trágico, em que se lançar ao "acaso", investir na "necessidade", ou tentar "escapar" são sempre apostas, movimentos, atos; ou seja, potencializar ou despotencializar a vida é sempre estar no jogo. A potência desbloqueada irrompe justo quando se afirma a impotência em querer controlar o próprio jogo. Afirmar o trágico é aceitar que o jogo - a vida - não tem dentro e fora; no limite, tentar escapar é jogar sempre cansado, até, quem sabe, chegar a um esgotamento e ser lançado a recomeçar o jogo.

Como, então, operar uma saúde que reconcilie potência desbloqueada a uma prudência que proporcione algum contorno aos movimentos, sem garantias de nenhuma ordem, e que não nos destrua em apostas insustentáveis ou lançamentos suicidas? No limite, como conciliar o contingente e a continência, sem que o primeiro se faça totalmente insustentável ou que o segundo esterilize a vida em ato?

$$
* * *
$$

A forma-Homem atualizada - a do sujeitoempreendedor e previdenciário -, para tentar lidar com o estado de risco iminente, apostou na promessa tecnocientífica sem se ater a sua ironia: a instância que prometia a possibilidade de prever e eliminar o risco da morte não natural também involucrava o caráter intempestivo da vida. E justo a necessidade voraz de prever ao vislumbrar controlar o intempestivo acabou por afirmar e dar relevo a sua existência.

Pois, quando o sujeito-previdenciário tenta, em vão, manipular o estado de risco iminente, faz do 
movimento frenético em direção à saúde-previdenciária uma alegoria exagerada e paranoica, que não somente é incapaz de transgredir o intempestivo como amplifica a própria impotência de previdência diante do acaso. Mas, se ainda não é possível decretar sua morte, a afirmação dessa impotência acaba por esgotar outra posição subjetiva, desbloqueando a forma-Homem para a possibilidade de outra posição, uma atualização, uma transvaloração da vida:

O homem é uma invenção cuja recente data a arqueologia de nosso pensamento mostra facilmente.
Se estas disposições viessem a desaparecer tal como apareceram, ... então se pode apostar que o homem se desvaneceria como, na orla do mar, um rosto de areia. (Foucault, 1966/2000, p. 536)

Se Foucault está certo em sua aposta, então podemos pensar que essa nova forma por vir será possível com o esgotamento produzido pelo ruído incessante e desestabilizador que zumbe do intempestivo e que subverte e arrebata a necessidade previdenciária. É quando o falhanço do controle conjuga o intempestivo não mais à noção de risco, mas a uma velha força de fora.

\title{
Health practices and subjectivation: the emergence of the preventative subject
}

\begin{abstract}
We analyze the subjectivities of the historicalrelationship between subjects and their health and its subsequent variations in modern health practices. As a starting point, referenced by the bibliography of subjectivity and/or health thinkers, we describe a short history of health practices throughout the twentieth century: in the early century, health had the body as its sole object; decades later, the risk factor is then included, turning lifestyles the object of control; the advancement of molecular science at the end of the same century leads to ambivalence in health, as it allows to regard the subject as virtually ill based on the imminent risk of genetic contingency, and technoscience itself promises to predict, prevent, and modify such condition. The results suggest a novel notion of preventative health as an imperative has emerged: one must produce health incessantly in the present to decrease risk and to guarantee a value-added life. Would preventive subjectivity evolve in a manner that updates the modern form of the subject?
\end{abstract}

Keywords: subjectivity, health, risk, future, preventive subject.

\section{Pratiques de santé et subjectivation : l'émergence du sujet préventif}

Résumé: Au cours historique de la relation entre les sujets et leur santé, nous sommes intéressés à analyser la subjectivité dans ce parcours et les variations subséquentes dans les pratiques de santé modernes. En partant des références bibliographie des penseurs de la subjectivité et/ou de la santé, nous avons construit une brève histoire des pratiques de santé au cours du XXe siècle: au début du siècle, la santé a pour seul objet le corps; des décennies plus tard, le facteur de risque a été ajouté, faisant des modes de vie objet du contrôle ; le progrès de la science moléculaire au tournant du même siècle engendre une ambivalence à la santé, en rendant le sujet virtuellement malade en raison du risque imminent de contingence génétique et c'est la technoscience elle-même qui promet de prévoir, de prévenir et de modifier cette condition. Notre point d'arrivé suggère l'émergence d'une notion de santé préventive comme impératif : il faut incessamment produire la santé dans le présent pour diminuer le risque et garantir plus-vie future. Une subjectivité préventive serait-elle utilisée pour actualiser la forme moderne du sujet?

Mots-clés: subjectivité, santé, risque, avenir, sujet préventif.

\section{Prácticas de salud y subjetivación: la emergencia del sujeto previsional}

Resumen: En la historia de la relación de los sujetos con la salud, nos interesa analizar los procesos de subjetivación y las variaciones en las prácticas de salud modernas. Con base en la bibliografía de pensadores de subjetividad/salud, forjamos una breve historia de las prácticas de salud a lo largo del siglo XX: a principios del siglo, la salud tiene el cuerpo como objeto; décadas después, se agrega el factor riesgo, haciendo los modos de vivir objeto de control; el avance de la ciencia molecular en el final del mismo siglo engendra una ambivalencia a la salud, cuando hace el sujeto virtualmente enfermo por el riesgo inminente de la contingencia genética, y la tecnociencia misma promete predecir, prevenir y modificar esta condición. Nuestra conclusión sugiere la aparición de una noción previsional de salud como un imperativo: producir salud incesantemente en el presente para disminuir el riesgo y garantizar más vida futura. ¿Se forjaría una subjetividad previsional que actualiza la forma moderna de sujeto?

Palabras clave: subjetividad, salud, riesgo, futuro, sujeto previsional. 


\section{Referências}

Deleuze, G. (1988). Sobre a morte do homem e o super-homem. In G. Deleuze, Foucault (pp. 132-142). São Paulo, SP: Brasiliense. (Trabalho original publicado em 1986)

Deleuze, G. (1992). Post-scriptum sobre as sociedades de controle. In G. Deleuze, Conversações (pp. 219-226). Rio de Janeiro, RJ: Editora 34. (Trabalho original publicado em 1990)

Deleuze, G. \& Guattari, F. (2014). Kafka: para uma literatura menor. Belo Horizonte, MG: Autêntica. (Trabalho original publicado em 1975)

Foucault, M. (1985). História da sexualidade I: a vontade de saber (6a ed.). Rio de Janeiro, RJ: Graal. (Trabalho original publicado em 1976)

Foucault, M. (1999). Em defesa da sociedade: curso no Collège de France (1975-1976) (2a ed.). São Paulo, SP: Martins Fontes. (Trabalho original publicado em 1997)

Foucault, M. (2000). As palavras e as coisas. São Paulo, SP: Martins Fontes. (Trabalho original publicado em 1966)

Foucault, M. (2006). O poder psiquiátrico: curso no Collège de France (1973-1974). São Paulo, SP: Martins Fontes. (Trabalho original publicado em 2003)

Foucault, M. (2011). Arte, epistemologia, filosofia e história da medicina. Rio de Janeiro, RJ: Forense Universitária.
Kafka, F. (1998). A construção. In F. Kafka, Um artista da fome/A construção (M. Carone, trad., pp. 63-108). São Paulo, SP: Companhia das Letras. (Trabalho original publicado em 1923)

Merhy, E. E. (2009). A clínica do corpo sem órgãos, entre laços e perspicácias. Em foco a disciplinarização e a sociedade de controle. Lugar Comum: Estudos Mídia, Cultura e Democracia, 27, 283-308. Recuperado de https://bit.ly/3bN9OY0

Rabinow, P. (1999). Antropologia da razão. Rio de Janeiro, RJ: Relume-Dumará.

Ribeiro, C. R. (2009). Jogo de dados. In J. G. Aquino \& S. M. Corazza (Orgs.), Abecedário: educação da diferença (pp. 102-105). Campinas, SP: Papirus.

Rolnik, S. (1995). Ninguém é deleuziano. Buenos Aires: Notaciones Abisales. Recuperado de https://bit.ly/2Yiifq4

Rose, N. (2013). A política da própria vida: biomedicina, poder e subjetividade no século XXI. São Paulo, SP: Paulus. (Trabalho original publicado em 2007)

Recebido: 01/05/2018

Revisado: 23/10/2019

Aprovado: 14/04/2020 